\title{
Respiratory Complications from Acute Corrosive Poisonings in Adults
}

\author{
Andon A. Chibishev, Natasa Simonovska, Cvetanka Bozinovska, Zanina Pereska, Ivica Smokovski, Marija Glasnovic \\ University Clinic of Toxicology and urgent internal medicine, University "Ss Cyril and Metodius", Medical faculty, Skopje, Republic of \\ Macedonia
}

Corresponding author: Andon Chibishev, MD, PhD. Address: Vodnjanska, 17, Skopje, Republic of Macedonia. Tel: 0038975303630. Email: toksikourgentna@gmail.com

\begin{abstract}
Introduction: Acute corrosive poisonings are caused by ingestion of corrosive chemicals which are most commonly used as household agents. Intoxications with these kind of agents produce numerous and severe post-corrosive complications of the upper gastrointestinal tract. On the other hand, our experience showed that corrosive agents may also cause injuries of the respiratory system, which makes the treatment very hard and additionally complicates the severe clinical condition of the patient. Objective: The aim of the study is to show the incidence of respiratory complications in acute corrosive poisonings, the need of various clinical investigations and also the treatment and final outcome of these kind of poisoning. Methods: We retrospectively analyzed clinical records of 415 patients hospitalized and treated at the University clinic for toxicology and urgent internal medicine, in Skopje, Republic of Macedonia, in the period between 2007 and 2011. The protocol consisted of methods for analyzing the systemic complications, with an accent on the post-corrosive respiratory complications. Results: From the total number of patients even 98 (23.61\%) exhibited systemic complications, from which 51 (52.04\%) are respiratory complications. The majority of patients are female $(n=40,78.43 \%)$ and the most common complication is pneumonia $(n=47)$. The youngest patient in this study was 14 and the oldest was 87 years old. Conclusion: Besides the gastrointestinal complications in the acute corrosive poisonings respiratory complications are also very often. They complicate the clinical state of patient and very often lead to fatal endings.
\end{abstract}

Key words: Corrosive poisonings, systemic complications, pneumonia, post-corrosive complications.

\section{INTRODUCTION}

Acute poisonings are caused by ingestion of acids, bases, salts, heavy metals, iodine tincture and numerous chemicals that are usually found in different products, mainly used for cleaning. Depending on their chemical composition and structure these substances can cause either colliquative or coagulative necrosis, and at the same time a wide range of gastrointestinal injuries which can lead to late post-corrosive complications such as stenosis, strictures, and less common esophageal or stomach cancer $(1,2)$. They are due to accidental or intentional ingestion of a corrosive substance in patients of different age groups. Most often these injuries can result in post corrosive complications such as stenosis and they can even end lethally due to perforation or tracheal necrosis $(3,4)$. Acute poisonings with corrosive substances are almost regularly followed by complications such as acute renal failure, DIC, fistula, pneumonia, anemia; they usually prolong the hospital stay of patients and can be reason for fatal end in patients during the chronic phase (5). Unlike some systemic complications such as acute renal failure or DIC, which mainly result from acetic acid poisonings, respiratory complications can be found in patients poisoned by almost any corrosive substance, and the severity of the respiratory injuries depend on the type and the concentration of the chemical cor- rosive agent (6). A large number of patients exhibit lesser post corrosive injuries and usually recover without serious complications (7). However, an even larger number of post corrosive poisonings result in serious chemical injuries and complications to the upper gastrointestinal tract and a high mortality rate. The post corrosive complications that include respiratory injuries are especially significant for determining the severity of acute corrosive poisonings. Mortality is most often caused by tracheal necrosis and perforation of the esophagus or stomach, followed by mediastinitis or peritonitis (8).

The purpose of this study was to investigate the incidence of respiratory complications in acute corrosive poisonings, the need for additional clinical examinations, course, treatment and outcome of acute corrosive poisonings.

\section{MATERIALS AND METHODS}

Data collected for a period of five years, from 2007 to 2011, was examined retrospectively, of patients ranging 14-90 years old, that were hospitalized and treated at the University Clinic for Toxicology in Skopje, Republic of Macedonia. The patient data included epidemiological variables such as age, sex, cause for poisoning, and the type of ingested corrosive substance. Systemic complications including the ones of the respiratory 
system, were observed and noted separately during the protocol for data collection. All patients that exhibited respiratory complications, were further questioned and their past respiratory illnesses such as bronchitis, asthma, fibrous changes of the lung tissues and others were recorded and taken into consideration. All patients were examined by otorhinolaryngologists, pulmonologists, and as needed were further examined by $\mathrm{x}$-rays and CT scans of the lungs and bronchoscopy.

\section{RESULTS}

During this study 415 clinical files of patients with acute corrosive poisonings were analyzed, of which 98 (23.61\%) developed systemic complications. Out of those 98 patients: 51 (52.04\%) had respiratory complication during their hospital stay, mostly pneumonia $(h=47) ; 2$ patients besides pneumonia also developed esophago-tracheal and esophago-broncial fistulas and two patients developed acute tracheal necrosis, 27 patients (27.55\%) developed acute kidney failure (AKF), 19 patients (19.38\%) developed secondary anemia and 1 patient (1.02\%) developed DIC.

Our main focus is on patients that exhibited respiratory complications, a total of 51 patients out of which $40(78.43 \%)$ are women while $11(21.56 \%)$ are men. The age interval of the patients is in the range of $42.9 \pm 16.5$ years, $\mathrm{Cl} 37.3-48.4$; youngest patient is 14 years old (minimal age value), and the oldest is 87 years old (maximum age value). Hydrochloric acid was the most often ingested chemical ( $\mathrm{n}=24,47.05 \%)$, sodium hydroxide was the second most common substance $(n=21,41.1 \%)$, followed by acetic acid ( $n=3,5.88 \%)$, than sulfuric acid $(n=2,3.92 \%)$ and finally bleach $(n=1,1.96 \%)$. Attempted suicide was the leading cause of the poisoning in 50 patients $(98.03 \%)$ and only 1 patient (1.96\%) accidently ingested the chemical. The length of the hospital stay is within the interval of 3 to 47 days, while the length of stay within the intensive care unit is between 2 to 25 days. The data collected is presented in Table 1.

\begin{tabular}{ll}
\hline Total number of patients & 51 \\
\hline Women $(\%)$ & $40(78.84)$ \\
Man $(\%)$ & $11(21.56)$ \\
\hline Age & $(42.9 \pm 16.5) ; \mathrm{Cl} 3.3-48.4$ \\
\hline Cause for poisoning $(\%)$ & $50(98.03)$ \\
Suicide & $27(6.5)$ \\
Accident & women/man $(\%)$ \\
\hline Type of corrosive substance, & $15 / 9(29.41 / 17-64)$ \\
$\mathrm{HCl}$ & $18 / 3(35.29 / 5.88)$ \\
$\mathrm{NaOH}$ & $2 / 0(3.92 / 0.00)$ \\
$\mathrm{CH} 3 \mathrm{COOH}$ & $2 / 0(0.48 / 0.00)$ \\
$\mathrm{H} 2 \mathrm{SO} 4$ & $1 / 0(1.96 / 0.00)$ \\
$\mathrm{NaClO} 4$ & $3-47$ \\
\hline Length of hospital stay (days) & $2-25$ \\
\hline Length of stay in intensive care (days) & \\
\hline
\end{tabular}

Table 1. Patients and their clinical characteristic

Data collected through direct and indirect questionnaires indicates that the patients reported to have difficulty breathing, felt like they were suffocating, had coughs and excessive production of saliva and felt overall weakness, when admitted to the hospital. Some patients developed fever, chest pain and cyanosis. Previous respiratory illness was found in 9 patients, of which 3 had chronic bronchitis- bronchial asthma, 3 had bronchiectasis, 1 patient had laryngeal carcinoma, 1 patient had bronchial carcinoma and 1 patient had pleurodiaphragmatic adhesions. All 51 patients required oxygen therapy, 5 of the patients needed intubation and assisted mechanical ventilation, and 2 patients needed tracheostomy. Besides oxygen therapy, the patients were administered with bronchodilators, antibiotics, corticosteroids, and symptomatic therapy. Four of the patients due to the severity of their respiratory complications died, 3 in the acute phase, during the first 96 hours following the ingestion of the corrosive substance, and 1 patient died in the chronic phase, 96 hours from the substance ingestion. Three patients died because of tracheal necrosis with acute mediastinitis, in a state of shock, while 1 patient died due to severe infectious complications and sepsis. The patient that developed sepsis was also found to have had bronchial asthma at the age of 3 years. Data represented in Table 2.

\begin{tabular}{ll}
\hline Symptoms & Number \\
\hline Difficult breathing & 51 \\
\hline Suffocation & 51 \\
\hline Coughs & 49 \\
\hline Excessive saliva production & 40 \\
\hline Raised fever & 32 \\
\hline Chest pain & 50 \\
\hline Cyanosis & 29 \\
\hline Previous illness of the respiratory tract & Number \\
\hline Chronic bronchial & 1 \\
\hline Bronchial asthma & 2 \\
\hline Bronchiectasis & 3 \\
\hline Laryngeal carcinoma & 1 \\
\hline Bronchial carcinomas & 1 \\
\hline Pleurodiaphragmatic adhesions & 1 \\
\hline Specific therapy & Number \\
\hline Oxygen therapy & 51 \\
\hline Intubation & 5 \\
\hline Tracheostomy & 2 \\
\hline Lethal outcome & 4 \\
\hline Tracheal necrosis (mediastinitis) & \\
\hline & \\
\hline
\end{tabular}

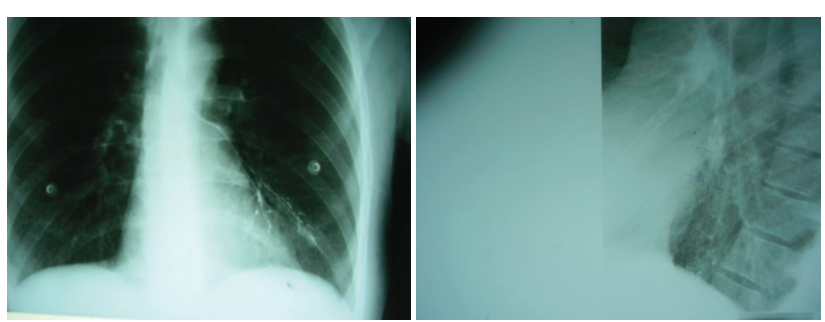

Figures 1a, 1b. X-ray findings in patient with esophago-tracheal-bronchial fistula

$$
\text { Severe infectious complications and sepsis } \quad(>96 x) 1
$$

Table 2. Symptoms, anamnestic data, death

\section{DISCUSSION}

The number of poisonings from corrosive chemicals is inclining, especially in less developed countries with lower health standards. Easy access to corrosive chemicals for the general public resulted in increased percentile of post-corrosive complications, which often lead to permanent disability in patients. The lack of appropriate laws for the import, licensing, packing and 

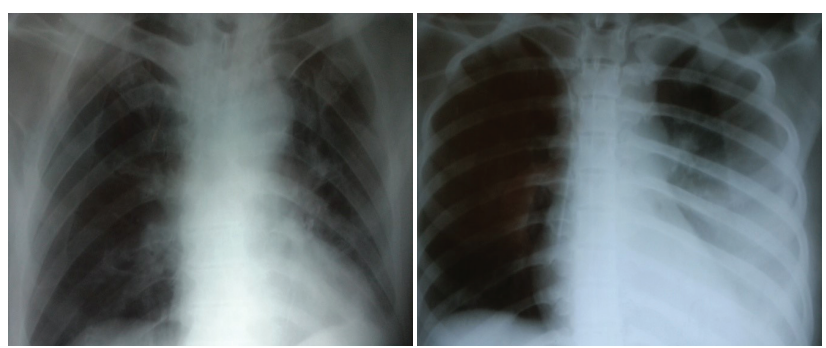

Figures 2a, 2b. X-rays of patients with corrosive poisonings

(bronchopneumonia, pulmonary consolidation, and pleural effusion)

transport of these dangerous chemicals, made them one of the most commonly abused substances $(9,10)$. The report from the American Center for Poisonings Control for 2011 indicates that from the total number of reported poisonings, a large number of 202056 cases were due to the use of cleaning products, under the group of corrosive chemicals. In a 5-year study conducted in Turkey, it has been found that $2.5 \%$ from the total number of poisonings belongs to the group of corrosive poisonings. While a study conducted in England and Wales, claims that one third from the total number of poisonings are caused by products used for the sanitation of households and most often found in adult patients, but the findings were identical among children as well $(11,12,13)$. For the evaluation of the extend of the damage caused by the ingestion of these substances, one needs to be aware of the reason for the ingestion, the nature and the amount of the ingested substance, the length of the exposure, how long before the patient is treated and the sex and age of the patient $(14,15)$. Most hospitals across the globe use aggressive methods and protocols, both conservative and surgical, for the treatment of patients with corrosive poisonings, consequently the rate of mortality and morbidity has significantly decreased in the past several years $(16,17)$.

Complications to the respiratory tract caused by corrosive chemicals quite often result in serious clinical state, frequently accompanied with gastrointestinal complications, causing death in patients, and are proven to be difficult to treat or cure. One patient in this study at the age of 70 accidentally ingested a small amount of methyl ethyl ketone peroxide, developing corrosive complications among others. The respiratory side-effects on the throat, the wind pipe and the lungs urged the patient to seek help at the emergency, after which he was hospitalized and treated urgently for obstructed airways, swelling of the pharynx, larynx, epiglottis and difficulty breathing. Re-examinations showed irritation, chemical burns and swelling of the upper respiratory tract. A similar case is observed in a 19 year old woman who intentionally ingested glutaraldehyde, commonly used as a sanitizer. This woman after 10 hours from the ingestion of the chemical, exhibited metabolic acidosis and respiratory distress, required hospitalization in intensive care and an endotracheal intubation due to the swelling of the larynx $(18,19)$. The patients in our study showed high rates of respiratory complications and side-effects probably due to the fact that the substance was intentionally ingested as attempt for suicide.

A large group of patients were part of a study conducted in Europe ( $n=3626)$, where they tested for the use of one of the most common household corrosive chemical, sodium hypo cholride, and its influence on allergic sensibilization. This study also portrays the high prevalence of respiratory complications especially in the group of mature patients, who ingested the chemical (20).
Another study where children are included, also portrays the prevalence of respiratory complications with varying symptoms further worsening the already dangerous clinical state of patients with acute corrosive poisonings. Much like our group of patient symptoms, these studies include the hyper production of saliva, oropharyngeal ulcerations, shortness of breath and the need for oxygen therapy. In a large number of cases, due to the inability of patients to breathe sufficiently, endotracheal intubation was performed and patients were breathing through mechanical ventilation (21). The danger from respiratory complications in corrosive poisonings needs to always be taken into consideration when creating the treatment plan and the therapy for the poisoned patients.

In another study, almost identical to our findings, a 65 year old man swallowed $600 \mathrm{ml}$ of alkaline detergent, who besides other symptoms had difficulty breathing and suffocation, respiratory dysfunction and respiratory distress. Despite intensive therapy with bronchodilators, steroids and epinephrine, the patient died after 4 day long hospital stay. The author further explains that the poisoning with this corrosive chemical besides the symptoms of exacerbation of bronchial asthma, it can also cause severe damage to the lung parenchyma (22).

The equivalent is manifested in a case of poisoning of a 39 year old woman who attempted suicide by ingesting a large amount of orto-phenylphenol. Where besides the acute respiratory distress syndrome, the chemical also inflicted diffused alveolar damages and severe lung fibrosis confirmed with a lung biopsy (23).

Our findings are supported by another case of a 66 year old woman who ingested a solution of $5.25 \%$ sodium hypochlorite $P_{x}=11.4$, after which besides the evident gastrointestinal complications, after the hospitalization in intensive care, the woman also developed metabolic acidosis and shortness of breath, as well as bilateral pneumothorax and pneumoperitoneum shown by $\mathrm{x}$-rays. Despite the intensive treatment and care in combination with endotracheal intubation and assisted breathing, the patient died as a result of heart complications. The outcome of this patient further supports our findings that respiratory complications in acute corrosive poisonings can be very serious and lead to death. Serious poisoning and lethal respiratory complications are observed in a case where a 16 year old woman abused sodium hypochlorite. This exemplifies our opinion that the ingestion of the corrosive substance, besides the post-corrosive complication to the upper gastrointestinal tract, can also result in harsh post-corrosive systemic respiratory complications which can lead to death $(24,25)$. The fact that there are only a small number of studies which focus on the post-corrosive respiratory complications, encourages us to keep following these symptoms and complications in acute corrosive poisonings as they can lead to further complications and even death.

\section{CONCLUSION}

In our study we show that when we are treating acute corrosive poisonings, it may be inexcusable to only focus on the post-corrosive complications to the upper gastrointestinal tract, which can lead to malpractice and difficulty when giving the diagnosis and/or the treatment. The large number of such complications and high mortality rate in all above mentioned cases, warn us, the clinicians treating acute corrosive poisonings, to pay special attention to the rest of the complications as well as the respiratory complications. 


\section{Conflict of interest: NONE DECLARED.}

\section{REFERENCES}

1. Ramasamy K, Gumaste VV. Corrosive ingestion in adults. J Clin Gastroenterol. 2003; 37: 119-124.

2. Akkose S, Bulut M, Armagan E, Cebicci H, Fedakar R.Acute poisoning in adults in the years 1996-2001 treated in the Uludag University Hospital, Marmara Region, Turkey. Clin Toxicol (Phila). 2005; 43: 105-109.

3. Goldman LP, Weigert JM. Corrosive substance ingestion: a review. American Journal of Gastroenterology. 1984; 79(2): 85-90.

4. Kikendall JN. Caustic ingestion injuries. Gastroenterol Clin North Am. 1991; 20: 847-857.

5. Chibishev A, Sikole A, Pereska Z, Chibisheva V, Simonovska N, Orovchanec N. Severe renal function impairment in adult patients acutely poisoned with concentrated acetic acid. Arh Hig Rada Toksikol. 2013 Mar; 64(1): 153-158.

6. Chibishev A, Pareska Z, Chibisheva V, Simonovska N. Clinical and epidemiological features of acute corrosive poisonings. Med Arh. 2012; 66(3 Suppl 1): 11-15.

7. Andreoni B, Marini A, Gavinelli M, Biffi R, Tiberio G, Farina, Rossi A. Emergency management of caustic ingestion in adults. Surg Today. 1995; 25: 119-124.

8. Ertekin C, Alimoglu O, Akyildiz H, Guloglu R, Taviloglu K. The results of caustic ingestions. Hepatogastroenterology. 51: 1397-1400.

9. Ananthakrishnan N, Subba Rao KSVK, Radjendiran P, Midcolon esophagocoloplasty for corrosive esophageal strictures. Aust N Z J Surg. 1993; 63: 389-395.

10. Ananthakrishnan N, Parthasarathy G, Vikram K. Chronic Corrosive Injuries of the Stomach - A Single Unit Experience of 109 Patients Over Thirty Years, World J Surg. 2010; 34: 758-764.

11. Bronstein A, Spyker A,Louis R, Cantilena JR, Green J, Rumack B, Dart R. Annual Report of the American Association of Poison Control Centers' National Poison Data System (NPDS): 28th Annual Report Clinical Toxicology. 2011; 49: 910-941.

12. Akkose S, Bulut M, Armagan E, Cebicci H, Fedakar R. Acute poisoning in adults in the years 1996-2001 treated in the Uludag University Hospital, Marmara Region, Turkey. Clin Toxicol (Phila). 2005; 43(2): 105-109.

13. Stiff G, Alwafi A, Rees BI, Lari J. Corrosive injuries of the oesophagus and stomach: experience in management at aregional paediatric centre. Ann R Coll Surg Engl. 1996; 78: 119-123.
14. Keh SM, Onyekwelu N, McManus K, McGuigan J. Corrosive injury to upper gastrointestinal tract: still a major surgical dilemma. World J Gastroenterol. 2006; 12: 5223-5228.

15. Gumaste VV, Dave PB. Ingestion of corrosive substances by adults. Am J Gastroenterol. 1992; 87: 1-5.

16. Andreoni B, Marini A, Gavinelli M, Biffi R, Tiberio G, Farina ML, Rossi A. Emergency management of caustic ingestion in adults. Surg Today. 1995; 25:119-124.

17. Dzhafarov ChM, Dzhafarov ECh. Surgical treatment of cicatricial stricture of the esophagus and stomach after chemical burn Khirurgiia (Mosk). 2007; (1): 25-28.

18. Bozdemir MN, Yildiz M, Seyhanli ES, Gurbuz S, Kilicaslan I, Karlidag T. Narrowing of airway caused by ingestion of methyl ethyl ketone peroxide.Hum Exp Toxicol. 2011 Dec; 30(12): 2002-2006.

19. Perera PM, Kularathne K, Gawarammana IB. Laryngeal edema and metabolic acidosis after Omnicide ingestion. Clin Toxicol (Phila). 2008 Nov; 46(9): 858-860.

20. Zock JP, Plana E, Antó JM, Benke G, Blanc PD, Carosso A, Dahlman-Höglund A, Heinrich J, Jarvis D, Kromhout H, Lillienberg L, Mirabelli MC, Norbäck D,Olivieri M, Ponzio M, Radon K, Soon A, van Sprundel M, Sunyer J, Svanes C, Torén K, Verlato G, Villani S, Kogevinas M. Domestic use of hypochlorite bleach, atopic sensitization, and respiratory symptoms in adults, J Allergy Clin Immunol. 2009 Oct; 124(4): 731-738.

21. Turner A, Robinson P. Respiratory and gastrointestinal complications of caustic ingestion in children. Emerg Med J. 2005 May; 22(5): 359-361.

22. Kamijo Y, Soma K, Inoue A, Nagai T, Kurihara K. Acute respiratory distress syndrome following asthma-like symptoms from massive ingestion of a monoethanolamine-containing detergent. Vet Hum Toxicol. 2004 Apr; 46(2): 79-80.

23. Cheng SL, Wang HC, Yang PC. Acute respiratory distress syndrome and lung fibrosis after ingestion of a high dose of orthophenylphenol. J Formos Med Assoc. 2005 Aug; 104(8): 585-587.

24. Ross MP, Spiller HA, Fatal ingestion of sodium hypochlorite bleach with associated hypernatremia and hyperchloremic metabolic acidosis.Vet Hum Toxicol. 1999 Apr; 41(2): 82-86.

25. Park JS, Min JH, Kim H, Lee SW. Esophageal perforation and mediastinitis after suicidal ingestion of $4.5 \%$ sodium hypochlorite [correction of hydrochlorite] bleach. Clin Toxicol (Phila). 2011 Oct; 49(8): 765-766. 